\title{
Uso de resíduos orgânicos na atenuação de contaminação por cobre de calda bordalesa
}

\section{Use of organic materials to attenuate copper contamination of Bordeaux mixture}

\section{Resumo}

\author{
Nathalia Sprovieri Cipoleta ${ }^{1(*)}$ \\ Laura Fernanda Simões da Silva² \\ Maria Leonor R. C. Lopes-Assad ${ }^{3(*)}$
}

Calda bordalesa $(\mathrm{CB})$, usada comumente em sistemas produção orgânica, pode aumentar os teores de cobre $(\mathrm{Cu})$ no solo. $\mathrm{O}$ objetivo deste trabalho foi avaliar o potencial de materiais ricos em compostos orgânicos na atenuação de contaminação por $\mathrm{Cu}$ em um solo argiloso. Foram testados fibra de coco (FC), bokashi (BO) e leonardita (LE), em três doses. Os ensaios foram montados em bancada, em tubos de PVC, com material de um Latossolo Vermelho argiloso, que recebeu três doses de $50,9 \mathrm{mg} \mathrm{Cu}$ na forma de CB. Foram realizadas amostragens regulares do percolado, ao longo de 47 dias de ensaio, para determinação da quantidade de $\mathrm{Cu}$ mobilizado após aplicação de água simulando a chuva no período do ensaio. Ao final, determinou-se o teor de $\mathrm{Cu}$ extraído por ácidos fraco e forte e estimou-se a quantidade de $\mathrm{Cu}$ que permaneceu retida. Observou-se que FC e BO proporcionaram diminuição do teor de $\mathrm{Cu}$ lixiviado em função de aumento das doses aplicadas, ao contrário da LE que proporcionou aumento de concentração de $\mathrm{Cu}$ no percolado em função do aumento das doses aplicadas. $\mathrm{BO}$ apresentou a menor concentração de $\mathrm{Cu}$ no percolado e as menores concentrações retidas no solo. LE apresentou a maior concentração de $\mathrm{Cu}$ no percolado e as maiores concentrações retidas no solo. Conclui-se que estudos sobre a utilização continuada de CB devem ser obrigatórios para monitorar solo e água, visando reduzir o risco de contaminação ambiental.

Palavras-chave: Fibra de coco. Bokashi. Leonardita. Contaminação do solo.

\section{Abstract}

Bordeaux mixture, commonly used in organic production systems, can increase copper $(\mathrm{Cu})$ levels in the soil. The objective of this work was to evaluate the potential of materials rich in organic compounds in the attenuation of $\mathrm{Cu}$ contamination in a clayey soil. Coconut fiber (FC), bokashi (BO) and leonardite (LE) were tested in three doses. The tests were mounted on a bench in PVC tubes with material of a Red Clay Latosol, which received three doses of $\mathrm{Cu}$ as a Bordeaux mixture. Regular percolate samplings

Msc.; Engenheira Ambiental; Mestre em Agroecologia e Desenvolvimento Rural pela Universidade Federal de São Carlos, UFSCar; Campus Araras;Araras-SP, Brasil; E-mail: nathaliacipoleta@hotmail.com

2 Dra.; Engenheira Agrônoma; Universidade Federal de São Carlos, UFSCar; Campus Araras; Araras-SP, Brasil; E-mail: Ifernandasimoesdasilva@gmail.com

3 Dra.; Agrônoma; Professora titular Aposentada da Universidade Federal de São Carlos, UFSCar, Campus Araras; Endereço: Rodovia Anhanguera, km 174, CEP: 13600-970,Araras-SP, Brasil; E-mail: assad@cca.ufscar.br; (*) Autora para correspondência

Recebido para publicação em 12/05/2017 e aceito em 05/06/2019

\begin{tabular}{llllll}
\hline Ambiência & Guarapuava (PR) & v.I5 n.2 & p. $289-307$ & Maio/Ago 2019 & ISSN I808 - 025I
\end{tabular}


were carried out, during the 47 days' trial, to determine the amount of $\mathrm{Cu}$ mobilized after application of water simulating rain during the test period. At the end, the content of $\mathrm{Cu}$ extracted by weak and strong acids was determined and the amount of $\mathrm{Cu}$ that remained retained was estimated. It was observed that $\mathrm{FC}$ and $\mathrm{BO}$ provided a decrease in the leached $\mathrm{Cu}$ content as a function of the increase of the applied doses, as opposed to the $\mathrm{LE}$ that provided an increase in $\mathrm{Cu}$ concentration in the percolate as a function of the increase of the applied doses. $\mathrm{BO}$ presented the lowest concentration of $\mathrm{Cu}$ in the percolate and the lowest concentrations retained in the soil. LE showed the highest concentration of $\mathrm{Cu}$ in the percolate and the highest concentrations retained in the soil. It is concluded that studies on the continued use of $\mathrm{CB}$ should be mandatory for monitoring soil and water, in order to reduce the risk of environmental contamination.

Keywords: Coconut fiber. Bokashi. Leonardite. Soil contamination.

\section{Introdução}

Atividades como agricultura, mineração e disposição de resíduos têm provocado aumento da concentração de metais pesados em solos elevando, consequentemente, os riscos de contaminação. Com o aumento da demanda da sociedade por alimentos mais saudáveis, com menor volume de resíduos nocivos ao ser humano e obtidos com mínimo impacto no ambiente, cresce o uso de materiais orgânicos para condicionamento e recuperação de solo e controle de pragas e doenças. Em sistemas agroecológicos, têm sido adotados insumos como calda bordalesa, calda viçosa, calda sulfocálcica, plantas e derivados de plantas para controle de pragas e de doenças, cujos efeitos no ambiente e na saúde humana têm sido investigados.

A calda bordalesa $(\mathrm{CB})$ é constituída por uma mistura de sulfato de cobre penta hidratado $(\mathrm{CuSO} 4.5 \mathrm{H} 2 \mathrm{O})$ e cal virgem $(\mathrm{CaO})$, que vem sendo mundialmente utilizada como fungicida e bactericida, tanto na vitivinicultura (MENEGAES, 2015) quanto na agricultura orgânica e em sistemas de produção agroecológicos (SEDIYAMA et al., 2014). Seu uso é conhecido desde o final do século XIX quando agricultores da região de Bordeaux, na França, verificaram, possivelmente por acaso, sua eficiência no controle de doenças em videira (SCHWENGBER et al., 2007). No Brasil, é amplamente empregada em culturas anuais como batata, tomate e pimentão (NASCIMENTO, 2016), bem como em culturas perenes como maçã (AMARANTE et al., 2015) e laranja (PETRY et al., 2015). A calda bordalesa pode ser produzida pelo agricultor, com baixo custo quando comparado com outros defensivos agrícolas (FELIX, 2005) e, em sistemas agroecológicos, deve ser usada no controle de pragas como último recurso (VIANNA JÚNIOR, 2015).

A utilização da CB sem controle adequado e por período prolongado pode causar aumento de Cu disponível no solo (CASALI et al., 2008) e a resistência das plantas às pragas, por via do fornecimento de nutrientes (SEDIYAMA et al., 2014). Quando a concentração de metais é alta, pode ocorrer inibição do crescimento das plantas e causar alterações nos microorganismos (CUNHA et al., 2014). Casali et al. (2008), em estudo em videiras do Rio Grande do Sul que receberam doses anuais de $\mathrm{CB}$ durante 40 anos, constataram aumento do teor total e das frações biodisponíveis de $\mathrm{Cu}$ do solo, nas camadas de $0-20 \mathrm{~cm}$ e $20-40 \mathrm{~cm}$, quando comparadas com solo sob mata natural, sendo que a maior parte do $\mathrm{Cu}$ dos solos cultivados com a videira encontrava-se retida na fração mineral, enquanto que no solo sob mata natural encontrava-se principalmente na matéria orgânica. Embora plantas restrinjam a absorção da 
maioria dos metais pesados do solo, protegendo seres humanos, animais e a vida selvagem da presença desses contaminantes (SILVA et al., 2007), inúmeros trabalhos demonstram que plantas cultivadas com altas concentrações de metais pesados podem oferecer risco à saúde humana e causar impactos no ambiente (BERTOL et al., 2010).

$\mathrm{O} \mathrm{Cu}$ é um dos metais que podem ser adicionados ao solo, tanto em sistemas de agricultura intensiva quanto em sistemas agroecológicos. É um micronutriente essencial para plantas e micro-organismos e presente na natureza, principalmente combinado com o enxofre, na forma de sulfeto de cobre. Porém, em grandes concentrações, pode ser tóxico, por inativar diversas enzimas citoplasmáticas, provocar estresse oxidativo, comprometer a fotossíntese e interferir no metabolismo de macro e micronutrientes, afetando, consequentemente, o crescimento das plantas (RODRIGUES et al., 2016). Além disso pode causar contaminação de solo e de águas superficiais e subterrâneas.

A matéria orgânica presente em fertilizantes ou resíduos orgânicos tem a capacidade de reter íons e complexar elementos tóxicos (VINHAL-FREITAS et al., 2010). Portanto, a utilização de materiais ricos em matéria orgânica pode ser uma importante forma de atenuação dos efeitos contaminantes do $\mathrm{Cu}$ em solos expostos à adição de doses elevadas desse metal. Alguns desses materiais, como dejetos suínos (BERTOL et al., 2010; LOPES et al., 2014a), resíduo urbano e lodo de estação de tratamento de esgoto (CANELLAS et al., 1999) e fibra de coco (SILVA et al., 2013) já são reconhecidos por sua capacidade de interação com metais no solo e são usados em sistemas orgânicos. Outros como bokashi e leonardita parecem carecer ainda de estudos sobre sua eficiência.

Resíduos de fibra de coco (FC), em especial do mesocarpo, têm sido empregados como material biossorvente de metais como cromo, chumbo e resíduos de óleos, tanto no solo como em águas residuárias, dado seu baixo valor econômico e por ser um produto renovável (COSTA et al. 2017; MOREIRA e SEO, 2017; SARMENTO, 2017; SILVA et al., 2013). O bokashi (BO) é um composto orgânico produzido da mistura de vários materiais orgânicos (esterco, palha, folhas verdes etc) ao qual são adicionadas fontes de energia (em geral melaço) e levedura (ALVAREZSOLIS et al.,2016). No Brasil, humatos como a leonardita (LE) são pouco utilizados na agricultura orgânica embora seu papel na fertilização de solos (BORCIONI et al., 2016; LIMA et al., 2011; LOBO, 2015) e na fitorremediação de Cu seja conhecido (VARGAS et al., 2016). A LE é um material com características semelhantes ao carvão, proveniente de depósitos orgânicos, muito rico em ácidos húmicos (ZANDONADI et al., 2014) e pode gerar alterações na estrutura do solo e na composição e eficiência da população microbiana (SUGIER et al., 2013). Preparações de LE já estão disponíveis comercialmente para aplicação na agricultura e podem ser adicionadas ao solo misturadas em água.

Em vista do exposto, objetivou-se com este trabalho avaliar o potencial de três materiais de origem orgânica (fibra de coco, bokashi e leonardita) na atenuação de contaminação por cobre proveniente de calda bordalesa aplicada em um solo argiloso.

\section{Material e Métodos}

O experimento foi conduzido em bancada, em ambiente de temperatura e umidade mantidas controladas, no Laboratório de Biotecnologia do Instituto de Pesquisas Científicas (IPECI) da Universidade Católica de Santos (UNISANTOS), entre 14 de setembro, quando foi 
feita a primeira aplicação de $20 \mathrm{~mL}$ de CB, e 30 de outubro de 2016, quando foi feita a última aplicação de $20 \mathrm{~mL}$ de CB.

O material de solo utilizado foi coletado na camada 0-20 $\mathrm{cm}$ de um Latossolo Vermelho argiloso em área experimental (22 $18^{\prime} \mathrm{S}$ e $47^{\circ} 23^{\prime} \mathrm{O}$, altitude de $690 \mathrm{~m}$ ) do Centro de Ciências Agrárias da Universidade Federal de São Carlos (UFSCar), em Araras (SP). As análises químicas realizadas no Laboratório de Análise Química de Solos e Planta da UFSCar - Araras apontaram $\mathrm{pH} \mathrm{CaCl}_{2}=5,6$, matéria orgânica $(\mathrm{MO})=34 \mathrm{~g} \mathrm{dm}^{-3}, \mathrm{P}-$ Resina $=46 \mathrm{~g} \mathrm{dm}^{-3}, \mathrm{~K}=4,1 \mathrm{mmol}_{\mathrm{c}}$ $\mathrm{dm}^{-3}, \mathrm{Ca}=10 \mathrm{mmol}_{\mathrm{c}} \mathrm{dm}^{-3}, \mathrm{Mg}=5 \mathrm{mmol}_{\mathrm{c}} \mathrm{dm}^{-3}, \mathrm{H}+\mathrm{Al}=28 \mathrm{mmol}_{\mathrm{c}} \mathrm{dm}^{-3}, \mathrm{Al}=0,4 \mathrm{mmol}_{\mathrm{c}} \mathrm{dm}^{-3}, \mathrm{~S}$ $=28 \mathrm{mg} \mathrm{dm}{ }^{-3}, \mathrm{~B}=0,07 \mathrm{mg} \mathrm{dm}{ }^{-3}, \mathrm{Cu}=15,7 \mathrm{mg} \mathrm{dm}^{-3}, \mathrm{Fe}=47 \mathrm{mg} \mathrm{dm}^{-3}, \mathrm{Mn}=434 \mathrm{mg} \mathrm{dm}^{-3}, \mathrm{Zn}$ $=5,5 \mathrm{mg} \mathrm{dm}^{-3}$, soma de bases $(\mathrm{SB})=18,8 \mathrm{mmol}_{\mathrm{c}} \mathrm{dm}^{-3}$, capacidade de troca de cátions $(\mathrm{CTC})=$ $46,8 \mathrm{mmol}_{\mathrm{c}} \mathrm{dm}^{-3}$, saturação por bases $(\mathrm{V})=40 \%$, e saturação por alumínio $(\mathrm{m})=2 \%$. A análise granulométrica indicou $550 \mathrm{~g} \mathrm{~kg}^{-1}$ de argila, $290 \mathrm{~g} \mathrm{~kg}^{-1}$ de silte e $160 \mathrm{~g} \mathrm{~kg}^{-1}$ de areia (SCAVAZZA et al.,2018). Todas as análises foram feitas de acordo com métodos descritos em Raij et al. (2001) e em Embrapa (1997).

O ensaio foi montado adaptando-se proposta de Lopes et al. (2014b). Inicialmente, foram retirados materiais de origem orgânica visíveis a olho nu. Em seguida, o material de solo foi destorroado manualmente e secado ao ar (temperatura ambiente de cerca de $25^{\circ} \mathrm{C}$ ) durante 15 dias. Posteriormente, $142 \mathrm{~g}$ de material de solo foram colocados em tubos de policloreto de vinila (PVC), de $40 \mathrm{~mm}$ de diâmetro e $15 \mathrm{~cm}$ de altura. Em seguida, foi distribuído em camadas ligeiramente compactadas de forma a simular a condição original de campo. Filtros de polipropileno foram colocados em uma das extremidades dos tubos, para que o material de solo não fosse carreado para o percolado.

$\mathrm{O}$ experimento foi dividido em duas etapas. Na primeira, foram feitas aplicações de $\mathrm{CB}$ e água e foi determinado o teor de $\mathrm{Cu}$ no percolado (etapa de lixiviação). Na segunda etapa, e utilizando o material de solo ao final da etapa anterior, o solo foi submetido a um processo de extração do $\mathrm{Cu}$ por meio de ácidos fraco e forte (etapa de retenção). Ao final do experimento, foram realizados cálculos para estimar os teores de $\mathrm{Cu}$ no percolado e os teores removidos por meio de ácidos e não removidos do Latossolo Vermelho argiloso utilizado.

\section{Lixiviação de Cu em solo adubado com materiais de origem orgânica}

Foram testadas três doses para cada um dos três tipos de materiais: bokashi (BO), fibra de coco (FC) e leonardita (LE) (Tabela 1). As doses de FC e de BO aplicadas foram definidas com base na literatura, adotando-se valores comumente usados em sistemas agroecológicos (VIANNA JÚNIOR, 2015). Como essas doses variam muito de um insumo para o outro, a quantidade de cada material aplicado no solo foi diferente. Esse procedimento permitiu observar os efeitos de cada tratamento, respeitando as propriedades e as interações de cada material com o solo. A aplicação de doses iguais para todos os tratamentos poderia gerar superdose ou dose insuficiente, o que inibiria ou aceleraria processos distintos. Todos os tratamentos foram feitos em triplicatas.

A FC foi pesada e misturada às $142 \mathrm{~g}$ de solo e, em seguida, foi colocada dentro dos tubos de PVC. O BO e a LE foram diluídos em $10 \mathrm{ml}$ de água destilada e borrifados na superfície do solo. O percolado gerado com a aplicação do $\mathrm{BO}$ e da LE foi recolhido e descartado. Na parte inferior dos tubos de PVC (Figura 1) foram posicionados frascos de plástico para a coleta do líquido excedente. 

Tabela 1 - Quantidades de material orgânico aplicadas em Latossolo Vermelho argiloso nos três tratamentos (T1, T2 e T3) com bokashi (BO), fibra de coco (FC) e leonardita (LE).

\begin{tabular}{ccccccc}
\hline \multirow{2}{*}{ Tratamentos } & \multicolumn{3}{c}{$\mathrm{FC}$} & \multicolumn{2}{c}{$\mathrm{BO}$} & \multicolumn{2}{c}{$\mathrm{LE}$} \\
\cline { 2 - 7 } & $\% \mathrm{v} / \mathrm{v}$ & $\mathrm{cm}^{3} /$ tubo & $\mathrm{g} \mathrm{m}^{-2}$ & $\mathrm{~g} /$ tubo & $\mathrm{g} \mathrm{kg}^{-1}$ & $\mathrm{~g} /$ tubo \\
\hline T1 & 3 & 3,8 & 150 & 0,188 & 1 & 0,142 \\
$\mathrm{~T} 2$ & 6 & 7,5 & 300 & 0,377 & 2 & 0,284 \\
T3 & 9 & 11,3 & 450 & 0,565 & 3 & 0,426 \\
\hline
\end{tabular}

\section{Figura 1 - Esquema de montagem dos tubos de PVC para ensaios de lixiviação.}

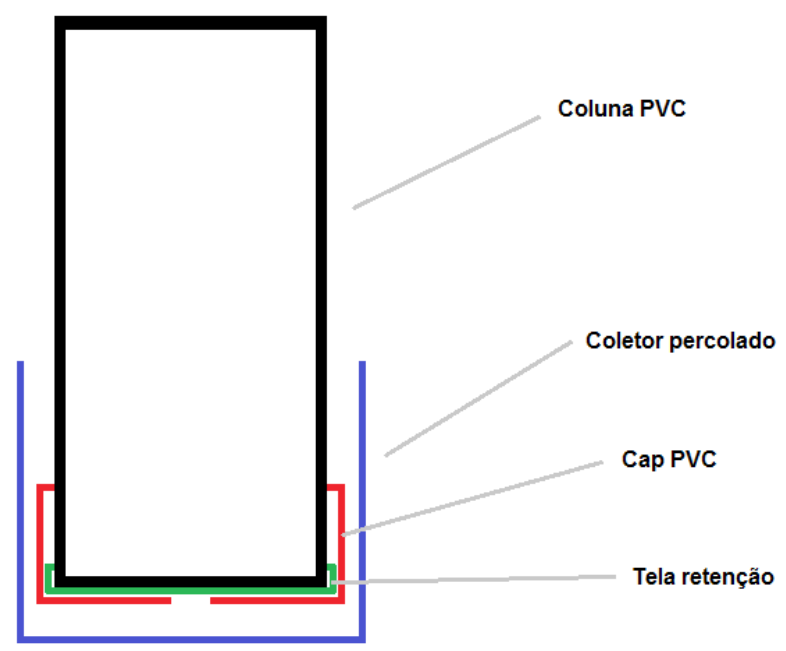

Após a montagem, e para assentar solo e material orgânico, foram aplicados $100 \mathrm{ml}$ de água destilada em cada um dos tubos. Esse percolado foi coletado e descartado. A quantidade de água a ser aplicada durante o ensaio foi determinada a partir da média mensal de chuva, utilizando-se a série histórica, de 1973 a 2014, da precipitação pluviométrica medida na Estação Climatológica da UFSCar - Araras. Com base nos cálculos da média de volume de chuva e na quantidade média de dias chuvosos no período, foram realizadas nove aplicações de $18 \mathrm{~mL}$ de água destilada, ao longo dos 47 dias de ensaio, simulando a chuva no período.

$\mathrm{O} \mathrm{Cu}$ foi adicionado por meio de três doses de $\mathrm{CB}$, aplicadas nos dias 14 e 30 de setembro e em 17 de outubro de 2016. A calda foi preparada na concentração de 1\%, utilizando $100 \mathrm{~g}$ de sulfato de cobre pentahidratado $\left(\mathrm{CuSO}_{4} \cdot 5 \mathrm{H}_{2} \mathrm{O}\right)$ e $100 \mathrm{~g}$ de cal hidratada $\left(\mathrm{Ca}(\mathrm{OH})_{2}\right)$ em $10 \mathrm{~L}$ de água, com base na formulação tradicionalmente adotada em hortas agroecológicas (VIANNA JÚNIOR, 2015). Cada dose correspondeu a $20 \mathrm{~mL}$ de CB, que representaram a 50,9 mg de $\mathrm{Cu}$. Assim, foram adicionados $1.075,3 \mathrm{mg} \mathrm{Cu} \mathrm{kg}{ }^{-1}$ que somados aos $15,7 \mathrm{mg} \mathrm{kg}^{-1}$ existentes no solo, representaram $1.091 \mathrm{mg} \mathrm{de} \mathrm{Cu} \mathrm{kg}^{-1}$, visando simular uma contaminação do solo. A Companhia Ambiental do Estado de São Paulo - CETESB considera que $760 \mathrm{mg} \mathrm{kg}^{-1} \mathrm{de} \mathrm{Cu}$ em solo agrícola é o valor de intervenção, isto é, acima dessa concentração existem riscos potenciais diretos e indiretos à saúde humana (CETESB, 2016). 
Cabe destacar que, em vinhedos do Sul do Brasil, existem registros de teores de $\mathrm{Cu}$ em solo de $900 \mathrm{mg} \mathrm{kg}^{-1}$ (BRUNETTO et al., 2008) até $3.200 \mathrm{mg} \mathrm{kg}^{-1}$ (MIRLEAN et al., 2007).

O percolado foi coletado um dia após cada aplicação de água e colocado separadamente em frascos âmbar. Cada frasco recebeu $1 \mathrm{~mL}$ de ácido nítrico para retirada do $\mathrm{Cu}$ presente na amostra, e foi analisado em espectrofotômetro de absorção atômica de chama ar-acetileno, para determinação dos teores de $\mathrm{Cu}$ que foram lixiviados no solo.

\section{Retenção de Cu em solo adubado com materiais de origem orgânica}

Ao final do ensaio de lixiviação, o solo foi retirado de cada um dos tubos, mantendo-se a forma cilíndrica da amostra. Em seguida, cada amostra foi fatiada em três porções de 3,3 cm de altura, correspondentes a topo, meio e final do tubo. De cada uma das porções, e nas três repetições, foram retiradas duas amostras de $1 \mathrm{~g}$ de solo e armazenadas em frasco âmbar com $10 \mathrm{~mL}$ de água destilada.

Nessa etapa, o objetivo foi avaliar a concentração de $\mathrm{Cu}$ adsorvido ao solo após extração por um ácido forte e um ácido fraco. Assim, as amostras de solo foram separadas em dois grupos: o primeiro recebeu 2,5 $\mathrm{mL}$ de ácido nítrico (ácido forte) e o segundo grupo, 2,5 $\mathrm{mL}$ de vinagre, contendo 5\% de ácido acético (ácido fraco). As 81 amostras (três materiais x três doses x três porções de solo $x$ três repetições) foram analisadas em espectrofotômetro de absorção atômica de chama ar-acetileno, para determinação dos teores de $\mathrm{Cu}$ retidos na amostra de solo.

\section{Avaliação de teores de cobre lixiviado e retido}

Os teores de $\mathrm{Cu}$ lixiviado foram definidos a partir das médias de teores de $\mathrm{Cu}$ no percolado. A avaliação do $\mathrm{Cu}$ retido foi feita considerando o total aplicado, as frações percoladas e aquelas extraídas por ácido fraco e ácido forte. Esses dados foram comparados com tratamentos de solo com calda bordalesa $(\mathrm{LV}+\mathrm{CB})$.

\section{Resultados e Discussão}

\section{Lixiviação de Cu em solo adubado com materiais de origem orgânica}

Observou-se uma tendência de aumento da lixiviação de $\mathrm{Cu}$ com o aumento das aplicações de $\mathrm{CB}$, sem uma relação evidente com a quantidade de material orgânico, ainda que os valores medidos tenham oscilado ao longo dos 47 dias de ensaio. $\mathrm{Na}$ comparação das médias de cada material não houve diferença entre as doses aplicadas (Tabela 2), e todos os tratamentos apresentaram coeficientes de variação, em relação à média, muitos altos, superiores a 30\% (PIMENTEL-GOMES, 2009). Isso pode ser devido à grande diferença entre os materiais usados e a forma de aplicação de cada um deles no material de solo.

Com exceção do valor medido em 26/09 no tratamento LE3, os valores medidos no percolado, após nove aplicações de água destilada, foram inferiores a $1,0 \mathrm{mg} \mathrm{L}^{-1}$, abaixo do limite recomendado pelo Ministério da Saúde, por meio da Portaria 518/2004 (BRASIL, 2005), para potabilidade de água sem risco à saúde, que considera o valor máximo permitido (VMP) de $\mathrm{Cu}$ igual a $2 \mathrm{mg} \mathrm{L}^{-1}$. Se considerarmos a concentração total de $\mathrm{Cu}$ medida no percolado ao final do ensaio (Tabela 2 e Figura 2), observa-se que FC e BO não ultrapassaram o VMP de 2,0 mg L-1 (BRASIL, 2005), mesmo tendo sido aplicados $1.091 \mathrm{mg}$ de $\mathrm{Cu} \mathrm{kg}^{-1}$. Entretanto, o tratamento com $3 \mathrm{~g} \mathrm{~kg}^{-1}$ de LE proporcionou um total de 2,11 $\mathrm{mg} \mathrm{Cu} \mathrm{kg}{ }^{-1}$. 
Tabela 2 - Médias de três repetições e análise de variância da concentração de cobre $(\mathrm{Cu})$, em $\mathrm{mg} \mathrm{L}^{-1}$, medida em água percolada, após nove aplicações de água destilada ao longo de 47 dias de ensaio, simulando a chuva no período, com fibra de coco (FC), bokashi (BO) e leonardita (LE), em três tratamentos. As aplicações de $20 \mathrm{~mL}$ de calda bordalesa, contendo $50,9 \mathrm{mg}$ de $\mathrm{mg}$ de $\mathrm{Cu}$, foram feitas no $1^{\circ}$ dia do experimento (14/9/), no $17^{\circ}$ dia (30/9) após medição de $\mathrm{Cu}$ e no $34^{\circ}$ dia (17/10).

\begin{tabular}{|c|c|c|c|c|c|c|c|c|c|c|c|}
\hline \multicolumn{2}{|c|}{ Tratamentos } & $21 / 09$ & $26 / 09$ & $30 / 09$ & $04 / 10$ & $10 / 10$ & $14 / 10$ & $19 / 10$ & $24 / 10$ & $30 / 10$ & \multirow{2}{*}{ Total } \\
\hline & & \multicolumn{9}{|c|}{ Concentração de $\mathrm{Cu}\left(\mathrm{mg} \mathrm{L}^{-1}\right)$ em água percolada } & \\
\hline & $\mathrm{T} 1$ & 0,04 & 0,06 & 0,00 & 0,08 & 0,05 & 0,04 & 0,43 & 0,69 & 0,13 & 1,52 \\
\hline \multirow[t]{3}{*}{$\mathrm{FC}$} & $\mathrm{T} 2$ & 0,06 & 0,05 & 0,08 & 0,12 & 0,07 & 0,11 & 0,06 & 0,06 & 0,10 & 0,71 \\
\hline & T3 & 0,03 & 0,05 & 0,03 & 0,05 & 0,05 & 0,10 & 0,12 & 0,16 & 0,09 & 0,68 \\
\hline & $\mathrm{T} 1$ & 0,19 & 0,06 & 0,05 & 0,05 & 0,05 & 0,05 & 0,06 & 0,16 & 0,16 & 0,96 \\
\hline \multirow[t]{3}{*}{$\mathrm{BO}$} & $\mathrm{T} 2$ & 0,10 & 0,07 & 0,00 & 0,04 & 0,06 & 0,07 & 0,08 & 0,10 & 0,11 & 0,66 \\
\hline & T3 & 0,09 & 0,10 & 0,00 & 0,06 & 0,08 & 0,06 & 0,09 & 0,05 & 0,11 & 0,63 \\
\hline & $\mathrm{T} 1$ & 0,11 & 0,08 & 0,00 & 0,06 & 0,03 & 0,05 & 0,12 & 0,13 & 0,14 & 0,72 \\
\hline \multirow[t]{3}{*}{$\mathrm{LE}$} & $\mathrm{T} 2$ & 0,03 & 0,09 & 0,00 & 0,06 & 0,05 & 0,05 & 0,02 & 0,12 & 0,82 & 1,24 \\
\hline & T3 & 0,08 & 1,69 & 0,00 & 0,05 & 0,05 & 0,08 & 0,02 & 0,06 & 0,09 & 2,12 \\
\hline & \multicolumn{11}{|l|}{$\mathrm{FC}$} \\
\hline \multicolumn{3}{|c|}{ Fonte da variação } & SQ & \multicolumn{2}{|c|}{ GL } & MQ & \multicolumn{2}{|c|}{$\mathrm{F}$} & valor-P & $\begin{array}{c}\mathrm{F} \\
\text { crítico }\end{array}$ & \\
\hline \multicolumn{2}{|c|}{ Entre grupos } & & 0,05 & \multicolumn{2}{|c|}{2,00} & 0,03 & \multirow{2}{*}{\multicolumn{2}{|c|}{1,32}} & 0,29 & 3,40 & \\
\hline \multicolumn{3}{|c|}{ Dentro dos grupos } & 0,45 & \multicolumn{2}{|c|}{24,00} & 0,02 & & & & & \\
\hline & Total & & 0,50 & 26,0 & & & & & & & \\
\hline \multicolumn{12}{|c|}{$\mathrm{BO}$} \\
\hline \multicolumn{2}{|c|}{ Entre grupos } & & 0,00 & \multicolumn{2}{|l|}{2} & 0,00 & \multirow{3}{*}{\multicolumn{2}{|c|}{0,85}} & 0,44 & 3,40 & \\
\hline \multicolumn{3}{|c|}{ Dentro dos grupos } & 0,04 & \multicolumn{2}{|c|}{24} & 0,00 & & & & & \\
\hline & Total & & 0,05 & 26 & & & & & & & \\
\hline \multicolumn{12}{|c|}{$\mathrm{LE}$} \\
\hline \multicolumn{3}{|c|}{ Entre grupos } & 0,11 & \multicolumn{2}{|l|}{2} & 0,05 & \multirow{2}{*}{\multicolumn{2}{|c|}{0,44}} & 0,65 & 3,40 & \\
\hline \multicolumn{3}{|c|}{ Dentro dos grupos } & 2,94 & \multicolumn{2}{|c|}{24} & 0,12 & & & & & \\
\hline \multicolumn{2}{|c|}{ Total } & & 3,05 & 26 & & & & & & & \\
\hline
\end{tabular}

FC: $T 1=3 \%, T 2=6 \%$ e T3 = 9\%; BO: T1 $=150 \mathrm{~g} \mathrm{~m}^{-2}, T 2=300 \mathrm{~g} \mathrm{~m}^{-2}$ e T3 $=450 \mathrm{~g} \mathrm{~m}^{-2} ; L E: T 1=1 \mathrm{~g} \mathrm{~kg}^{-1}, \mathrm{~T} 2=2 \mathrm{~g}$ $\mathrm{kg}^{-1}$ e T3 $=3 \mathrm{~g} \mathrm{~kg}^{-1}$.

Nesse ensaio, observou-se que, nos tratamentos com FC e BO, quanto maior a concentração de material orgânico no solo, menor a concentração de $\mathrm{Cu}$ no percolado, indicando maior retenção, ao contrário dos tratamentos com LE que apresentaram aumento de teores de $\mathrm{Cu}$ em função do aumento das doses de LE (Figura 2). Cabe destacar que durante o experimento foi observada lixiviação de LE no tratamento com maior dose, o que explicaria a maior concentração de $\mathrm{Cu}$ no percolado.

O potencial de humatos estáveis como a $\mathrm{LE}$ na retenção de cátions como o $\mathrm{Cu}$ é ainda pouco conhecido e seu papel parece estar mais relacionado com o aumento da absorção de nutrientes 
Figura 2 - Concentração total de cobre (Cu), em mg L-1, no percolado de Latossolo Vermelho argiloso, tratado com fibra de coco (FC3\%, FC6\% e FC9\%), bokashi (BO150 $\mathrm{g} \mathrm{m}^{-2}$, BO300 $\mathrm{g} \mathrm{m}^{-2} \mathrm{e}$ B0450 $\mathrm{g} \mathrm{m}^{-2}$ ) e leonardita (LE1 $\mathrm{g} \mathrm{kg}^{-1}$, LE2 $\mathrm{g} \mathrm{kg}^{-1} \mathrm{e}$ LE3 $\mathrm{g} \mathrm{kg}^{-1}$ ), que receberam $60 \mathrm{~mL}$ de calda bordalesa em três doses e $162 \mathrm{~mL}$ de água destilada em nove doses, durante 47 dias.

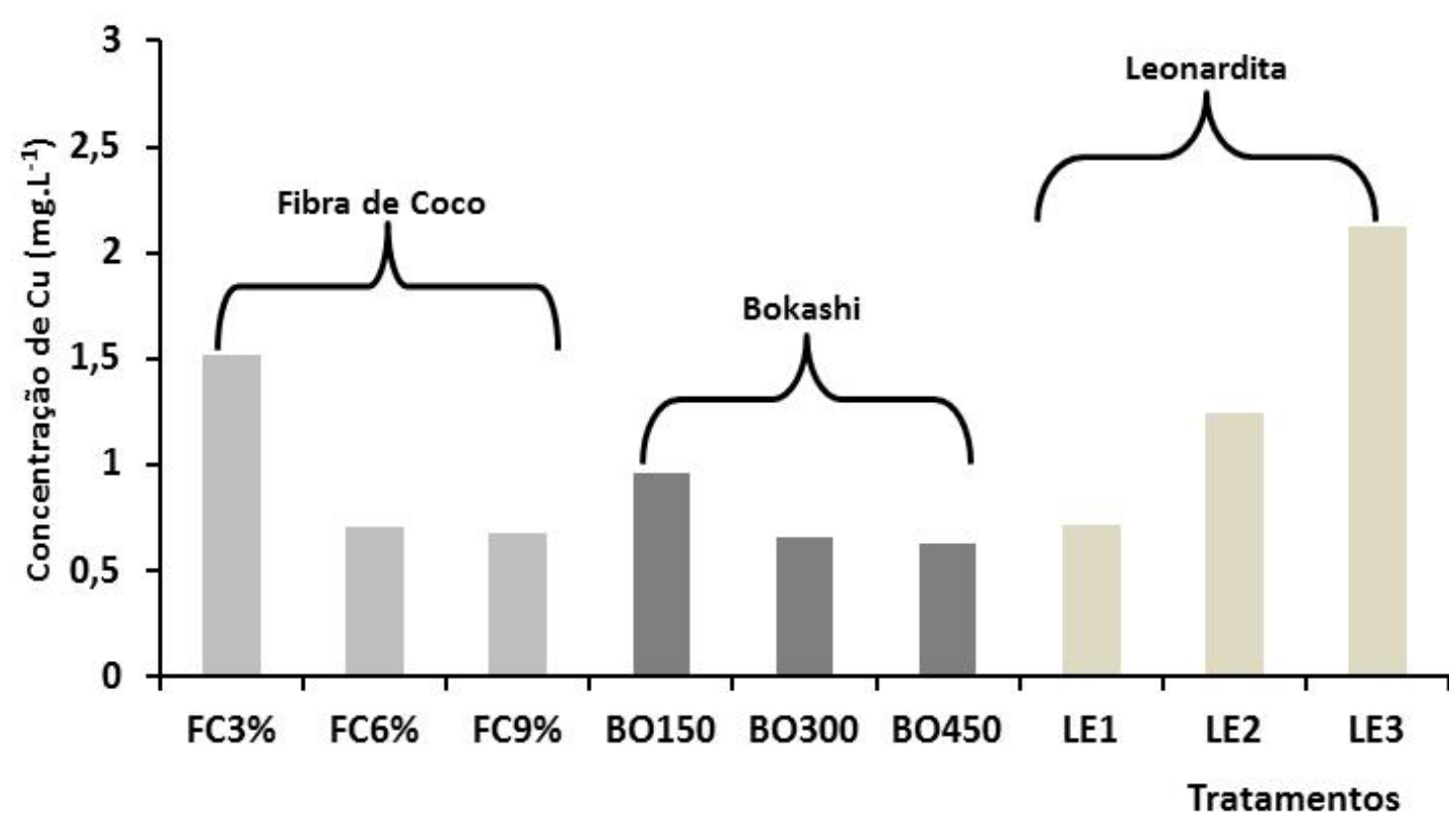

FC3\% $=3 \%$ de fibra de coco, FC6 $\%=6 \%$ de fibra de coco, FC9\% = 9\% de fibra de coco; BO150 = = $150 \mathrm{~g} \mathrm{~m}^{-2} \mathrm{de}$ bokashi, $B O 300=300 \mathrm{~g} \mathrm{~m}^{-2}$ de bokashi, $B O 450=450 \mathrm{~g} \mathrm{~m}^{-2}$ de bokashi; $L E 1=1 \mathrm{~g} \mathrm{~kg}^{-1}$ de leonardita, $L E 2=2 \mathrm{~g} \mathrm{~kg}^{-1}$ de leonardita e LE3 $=3 \mathrm{~g} \mathrm{~kg}^{-1}$ de leonardita.

por plantas (ZANDONADI et al., 2014) o que poderia indicar baixa capacidade de retenção de $\mathrm{Cu}$ no material. Com efeito, Lima et al. (2011), usando LE comercial, encontraram aumento de $\mathrm{Cu}$ em folhas de tomateiro quando cultivadas em doses de 20 a $80 \mathrm{~L} \mathrm{ha}^{-1}$, enquanto que David et al. (1994) observaram aumento no teor de $\mathrm{Cu}$ nas raízes de tomateiro em tratamento com $1280 \mathrm{mg} / \mathrm{L}$ de ácido húmico na forma de LE.

Por outro lado, alguns estudos apontam a capacidade de retenção de metais pela FC. Costa et al. (2017), por exemplo, constataram a eficiência da FC em adsorver íons $\mathrm{Cr}$ (III), em valores de $\mathrm{pH}$ mais elevados, e atribuíram essa eficiência à presença na $\mathrm{FC}$ de sítios ativos dissociados e/ ou desprotonados. Com efeito, a FC apresenta morfologia porosa e superfície irregular, que lhe permitem adsorver metais nos interstícios do material, conforme observaram Silva et al. (2013) analisando por microscopia eletrônica de varredura FC utilizada como material adsorvente de metais presentes em efluente de indústria de tintas à base de água.

$\mathrm{O}$ BO atuou de forma eficiente na retenção do metal, proporcionando as menores quantidades de $\mathrm{Cu}$ no percolado (Figura 2). Casali et al (2008) indicam que solos com baixos teores de óxidos, como o do experimento, permitem uma maior adsorção do $\mathrm{Cu}$ aos grupos funcionais da matéria orgânica. Ferreira et al. (2017) constataram, a partir da análise química de BO, que o composto possui alta concentração de matéria orgânica e baixa relação $\mathrm{C}$ : N, aumentando seu poder de retenção de $\mathrm{Cu}$. Como o $\mathrm{BO}$ apresenta composição orgânica variada, isso poderia estar dificultando a lixiviação do $\mathrm{Cu}$. 


\section{Retenção de Cu em solo adubado com materiais de origem orgânica}

Os teores de $\mathrm{Cu}$ extraídos das diferentes porções de solo (topo, meio e fim), em função da ação de um ácido fraco e um ácido forte estão representados na figura 3. Observou-se em todos os tratamentos que a amostra da parte superior (topo) do tubo apresentou a maior concentração de $\mathrm{Cu}$ extraído (Figura 3), indicando a baixa mobilidade desse metal em presença de materiais orgânicos. Casali et al. (2008) constataram aumento do teor total e das frações biodisponíveis de $\mathrm{Cu}$ do solo, nas camadas de $0-20 \mathrm{~cm}$ e $20-40 \mathrm{~cm}$, quando comparadas com solo sob mata natural, sendo que a maior parte do $\mathrm{Cu}$ dos solos cultivados com a videira encontrava-se retida na fração mineral, enquanto que no solo sob mata natural encontrava-se principalmente na matéria orgânica.

Nas amostras tratadas com FC (Figura 3A), a maior concentração de Cu extraído do solo se deu na dose de $9 \%$ com uso de ácido fraco. Nos tratamentos com LE, as quantidades de $\mathrm{Cu}$ extraídas foram menores, quando comparadas com os outros tratamentos (Figura 3C). As concentrações mais elevadas de $\mathrm{Cu}$ foram observadas na camada topo dos tratamentos com BO (Figura 3B), que ultrapassaram o valor de referência de qualidade (VRQ) de 35,0 mg kg-1 (CETESB, 2016), com exceção de BO2 na extração com ácido fraco.

Características do solo como a granulometria, estrutura, teor de matéria orgânica, CTC e mineralogia das argilas, influenciam diretamente na mobilidade dos metais pesados, interferindo no seu transporte pela coluna de solo (TITO et al., 2012; SMANHOTTO et al., 2010). O Cu é um elemento pouco móvel e sua solubilidade no solo é controlada por reações de adsorção / dessorção, precipitação e complexação. Florentino et al. (2019) constataram que em Latossolos de baixa fertilidade sob plantio de Eucalyptus, depois de dez a 17,2 anos após a primeira e única aplicação de lodo de esgoto, o teor de $\mathrm{Cu}$ nos solos mostrou-se maior, em relação a tratamentos sem lodo de esgoto e sem fertilização e com solo que recebeu apenas fertilizantes minerais, especialmente em doses mais altas (20-40 $\mathrm{Mgha}^{-1}$ ) de lodo, ainda que se mantendo em teores inferiores o VRQ de 35,0 $\mathrm{mg} \mathrm{kg}^{-1}$ (CETESB, 2016).

$\mathrm{O} \mathrm{Cu}$ em processo de percolação pode ser retido por boa parte dos solos ricos em matéria orgânica, que apresentem óxidos de ferro, alumínio e manganês na sua formação (SMANHOTTO et al., 2010). Por ter alta razão de complexação pela matéria orgânica do solo, o Cu dificilmente se torna extraível com extratores fracos (SMANHOTTO et al.,2010). No presente experimento, nas camadas mais interiores da amostra, o ácido forte foi mais efetivo do que o ácido fraco na extração do $\mathrm{Cu}$ (Figura 3). Quando na superfície da amostra, o ácido fraco teve capacidade de extrair maior concentração do metal, indicando que o $\mathrm{Cu}$ estaria mais disponível nessa região. Esse comportamento pode estar relacionado com características como porosidade do solo ao longo do tubo, que provocaria diferentes taxa de infiltração de água

\section{Balanço de teores de cobre}

$\mathrm{O}$ balanço entre $\mathrm{Cu}$ percolado, removido por meio de ácidos fraco e forte e não removido (Tabela 3) evidencia que os ácidos utilizados removeram apenas uma pequena parte do $\mathrm{Cu}$ adicionado por meio de $\mathrm{CB}$. Tanto nos tratamentos com adição de material orgânico, quantos no tratamento controle $(\mathrm{LV}+\mathrm{CB})$. $\mathrm{Em} \mathrm{LV}+\mathrm{CB}$, houve diminuição do $\mathrm{Cu}$ percolado, evidenciando o papel alcalinizante da calda (FELIX, 2005), que promove a formação de vários compostos, destacando-se o hidróxido de cobre, que é insolúvel em água. As diferenças quanto ao balanço (Tabela 3) podem indicar diferenças no grau de complexação 
Figura 3 - Quantidade de cobre ( $\mathrm{Cu})$, em mg L-1, extraída de Latossolo Vermelho argiloso com (A) fibra de coco, (B) bokashi e (C) leonardita, por meio de um ácido fraco (vinagre) e um ácido forte (ácido nítrico), ao longo de 47 dias.
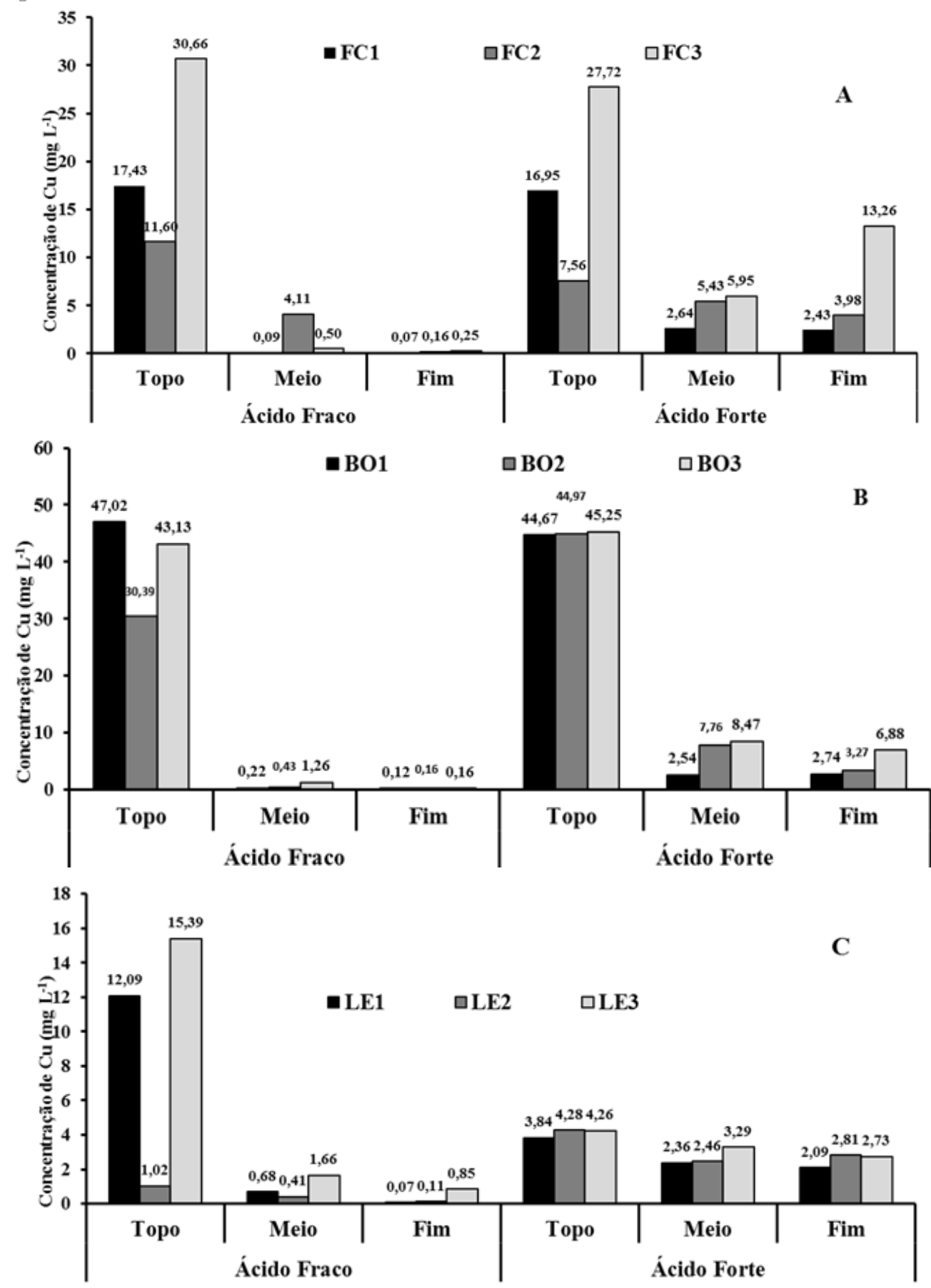

$F C 1=$ solo $+3 \%$ FC; FC2 = solo $+6 \%$ FC; FC3 = solo $+9 \%$ FC; BO1 = solo $+150 \mathrm{~g} \mathrm{~m}-2 ; B O 2=$ solo $+300 \mathrm{~g} \mathrm{~m}-2$ $B O ; B O 3=$ solo + $450 \mathrm{~g} \mathrm{~m}-2 \mathrm{BO} ; \mathrm{LE} 1=$ solo + $1 \mathrm{~g} \mathrm{kg-1} \mathrm{LE;} \mathrm{LE2} \mathrm{=} \mathrm{solo} \mathrm{+} 2 \mathrm{~g} \mathrm{~kg}-1 \mathrm{LE} ; \mathrm{LE} 3=$ solo $+3 \mathrm{~g} \mathrm{~kg}-1 \mathrm{LE}$.

de $\mathrm{Cu}$ com os materiais orgânicos adicionados. Isso porque, como o átomo de $\mathrm{Cu}$ possui na camada eletrônica mais externa um elétron desemparelhado e, na camada logo abaixo 18 elétrons, é bastante instável e perde elétrons facilmente, apresentando maior capacidade de compartilhamento de elétrons com diferentes grupos funcionais com insuficiência eletrônica presentes nos ácidos húmicos (CANELLAS et al., 1999; CANELLAS et al., 2008). 


\section{Tabela 3 - Teor de Cu percolado, removido por meio de ácidos fraco (vinagre) e forte (nítrico), não removido e porcentagem do total não removido de Latossolo Vermelho argiloso tratado com diferentes doses de fibra de coco (FC), bokashi (BO) e leonardita (LE), após aplicação de $60 \mathrm{~mL}$ de calda bordalesa contendo $152,7 \mathrm{mg} \mathrm{L}^{-1}$ de cobre, em 47 dias de experimento.}

\begin{tabular}{|c|c|c|c|c|c|c|c|}
\hline \multirow{3}{*}{ Trat. $^{1}$} & \multirow{2}{*}{$\begin{array}{c}\mathrm{Cu} \text { no } \\
\text { percolado }\end{array}$} & \multicolumn{2}{|c|}{ Ácido fraco } & \multirow{2}{*}{$\begin{array}{l}\mathrm{Cu} \text { não } \\
\text { removido }\end{array}$} & \multicolumn{2}{|c|}{ Ácido forte } & \multirow{2}{*}{$\begin{array}{l}\mathrm{Cu} \text { não } \\
\text { removido }\end{array}$} \\
\hline & & $\underset{\text { extraído }}{\mathrm{Cu}}$ & $\begin{array}{l}\text { Cu não } \\
\text { removido }\end{array}$ & & $\underset{\text { extraído }}{\mathrm{Cu}}$ & $\begin{array}{l}\text { Cu não } \\
\text { removido }\end{array}$ & \\
\hline & \multicolumn{3}{|c|}{------------- $\mathrm{mg} \mathrm{L} \mathrm{L}^{-1}$-------------- } & $\%$ & \multicolumn{2}{|c|}{ 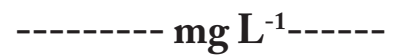 } & $\%$ \\
\hline $\mathrm{LV}+\mathrm{CB}$ & 1,256 & 15,674 & 135,770 & 88,9 & 28,791 & 122,653 & 80,3 \\
\hline FC1 & 1,519 & 17,597 & 133,584 & 87,5 & 22,023 & 129,157 & 84,6 \\
\hline $\mathrm{FC} 2$ & 0,705 & 15,876 & 136,119 & 89,1 & 16,969 & 135,026 & 88,4 \\
\hline FC3 & 0,690 & 31,403 & 120,607 & 79,0 & 46,93 & 105,08 & 68,8 \\
\hline BO1 & 0,837 & 47,349 & 104,514 & 68,4 & 49,946 & 101,917 & 66,7 \\
\hline $\mathrm{BO} 2$ & 0,621 & 30,984 & 121,095 & 79,3 & 56,000 & 96,079 & 62,9 \\
\hline $\mathrm{BO} 3$ & 0,643 & 44,55 & 107,506 & 70,4 & 60,589 & 91,467 & 59,9 \\
\hline LE1 & 0,729 & 12,837 & 139,134 & 91,1 & 8,287 & 143,684 & 94,1 \\
\hline LE2 & 1,248 & 1,535 & 149,917 & 98,2 & 9,55 & 141,902 & 92,9 \\
\hline LE3 & 2,109 & 17,899 & 132,692 & 86,9 & 10,271 & 140,32 & 91,9 \\
\hline
\end{tabular}

${ }^{1}$ Trat. (Tratamentos): $L V+C B=$ solo + calda bordalesa; $F C 1=$ solo $+3 \% F C ; F C 2=$ solo $+6 \% F C ; F C 3=$ solo $+9 \%$ $F C ; B O 1=$ solo $+150 \mathrm{~g} \mathrm{~m}^{-2} ; B O 2=$ solo $+300 \mathrm{~g} \mathrm{~m}^{-2} B O ; B O 3=$ solo $+450 \mathrm{~g} \mathrm{~m}^{-2}$ BO; LE1 = solo + $1 \mathrm{~g} \mathrm{~kg}^{-1} \mathrm{LE} ; \mathrm{LE2}$ $=$ solo $+2 \mathrm{~g} \mathrm{~kg}^{-1} \mathrm{LE} ; \mathrm{LE} 3=$ solo $+3 \mathrm{~g} \mathrm{~kg}^{-1} \mathrm{LE}$.

No ensaio aqui conduzido, em condições de laboratório, buscou-se simular condições de campo em sistemas de produção agroecológicos, mas foram utilizadas doses elevadas de $\mathrm{Cu}$ aplicadas em menos de 50 dias. Além disso, simulou-se apenas a camada superficial e solos como o utilizado neste ensaio possuem mais de $1 \mathrm{~m}$ de profundidade e, frequentemente, apresentam mais de $2 \mathrm{~m}$ de material rico em óxidos e hidróxidos de ferro e ou de alumínio. O solo utilizado no experimento é argiloso e muito intemperizado, com estrutura bem desenvolvida e com formação marcada por perda de sílica e de bases. Nesse ambiente, a baixa mobilidade do Cu é acentuada pelo teor de argila e pelo aumento residual de óxidos de oxi-hidróxidos de ferro e de alumínio (BERTOL et al., 2010). Esse comportamento pode ser afetado se houver aumento no aporte do metal no solo. Ainda assim, constatou-se que os materiais orgânicos utilizados atuaram de forma efetiva fazendo com que a lixiviação de $\mathrm{Cu}$ tenha sido, de modo geral, baixa (Tabela 2), principalmente quando comparadas, ao que foi adicionado. Mesmo no tratamento com LE em maior concentração (Tabela 2), o teor de Cu não ultrapassou 1,4\% do total adicionado (152,7 $\mathrm{mgL}^{-1}$ ). Esse resultado foi muito próximo dos valores encontrados por Bertol et al. (2010). Segundo Felix (2005), a CB é um material alcalino, que imobiliza ou dificulta a mobilidade do $\mathrm{Cu}$. No entanto, sucessivas aplicações tendem a aumentar o conteúdo de $\mathrm{Cu}$. Por isso, manutenção de conteúdos elevados de compostos orgânicos em solos que utilizam esse fungicida pode auxiliar na retenção do metal, o que explicaria a baixa concentração de $\mathrm{Cu}$ nos percolados.

Quando em contato com a matéria orgânica, o $\mathrm{Cu}$ é retido mais facilmente por ácidos húmicos e fúlvicos (SMANHOTTO et al., 2010). No experimento, o tratamento caracterizado 
pela presença de ácidos húmicos foi a LE. Entretanto, esse tratamento foi o que apresentou os teores mais altos de $\mathrm{Cu}$ no percolado (Tabela 2 e Figura 2), provavelmente porque houve lixiviação de LE no percolado durante o experimento. Com efeito, durante o experimento, observou-se que o percolado de LE apresentou coloração escura, principalmente em LE2 e LE3.

Solos com elevado intemperismo geralmente apresentam grande profundidade o que thes confere grande poder de filtrar solutos que venham a percolar. Dada a baixa mobilidade do $\mathrm{Cu}$ no solo, a tendência é que o $\mathrm{Cu}$ adicionado por meio de insumos ricos nesse metal permaneça nas camadas mais superficiais. Por isso, em solos argilosos, altamente intemperizados e profundos, é recomendável adotar práticas de manejo conservacionista que contenham o escoamento superficial e favoreçam a infiltração da água (BERTOL et al., 2010).

Cabe destacar que o $\mathrm{Cu}$ não percolado no solo não representa necessariamente contaminação. $\mathrm{O} \mathrm{Cu}$ é adsorvido no solo por ligações físico-químicas com diferentes graus de energia e sua labilidade e a capacidade de adsorção do solo são dependentes do ligante, das quantidades de argilominerais, óxidos e hidróxidos de ferro, alumínio e manganês, carbonatos e matéria orgânica, além da condição geoquímica, especialmente pH e CTC (BRADL, 2004; CASALI et al.; 2008; CANELLAS et al., 2008; MENEGAES, 2015). Sua adsorção ocorre primeiramente nos sítios de ligação mais ávidos, com maior afinidade pelos grupos funcionais dos constituintes orgânicos e o $\mathrm{Cu}$ remanescente é redistribuído em frações que são retidas com menor energia, consequentemente de maior disponibilidade e mobilidade (BRUNETTO et al., 2014; TIECHER et al., 2016). Isso confere grande importância à manutenção dos teores de matéria orgânica para aumentar a capacidade do solo de acumular $\mathrm{Cu}$ e reduzir os riscos de contaminação.

Smanhotto et al. (2010) observaram que o Cu é retido mais facilmente pelos ácidos húmicos e fúlvicos. A ligação de $\mathrm{Cu}$ com esses ácidos forma complexos estáveis de difícil extração e mobilidade. Isso fica evidente quando observada a porcentagem de retenção de $\mathrm{Cu}$ no solo pelas amostras tratadas com LE no experimento, que permaneceram acima de 90\%. Houve menor remoção por ácidos no tratamento com LE (Tabela 3), sendo que o aumento da concentração desse material orgânico não implicou aumento da retenção de $\mathrm{Cu}$.

A FC também mostrou eficiência na manutenção do $\mathrm{Cu}$ no solo, com porcentagens de retenção por volta de $80 \%$, ao contrário do observado em BO, cuja retenção foi inferior a 70\% e diminuiu com o aumento da dose aplicada (Tabela 3). Silva et al. (2013) observaram a capacidade de retenção de $\mathrm{Cu}$ pela $\mathrm{FC}$ e afirmam que essa característica se deve à composição da fibra, com predominância de lignina e celulose, biopolímeros reconhecidos na eficiência de remoção de metais pesados. Além disso, outros grupos funcionais presentes na FC e sua grande porosidade facilitam a adsorção de metais.

A LE é a principal fonte utilizada para extração de substâncias húmicas nos EUA e Europa, enquanto que no Brasil o mais comum é a turfa (ZANDONADI et al., 2014). Apesar de ainda ser pouco utilizada no Brasil, esse ensaio comprovou a eficiência de LE na retenção de Cu no solo. Entretanto, são necessários estudos mais aprofundados sobre seu comportamento em solos tropicais visto, que quantidades elevadas de $\mathrm{Cu}$ podem ser mobilizadas, principalmente se forem usados produtos fitossanitários à base de $\mathrm{Cu}$.

O uso de compostos na agricultura orgânica e de transição agroecológica, como a CB pode causar danos aos envolvidos, sendo necessário cuidado e monitoramento, para que não se perca o apelo ambiental trazido por esse novo olhar sobre os cultivos agrícolas. Isso porque o excesso de $\mathrm{Cu}$ em solos, água e alimentos pode causar doenças graves aos seres humanos e animais, além 
de ser um grande problema ambiental, quando avaliadas as características de bioacumulação de metais no ambiente.

\section{Conclusão}

Nos tratamentos com fibra de coco e com bokashi a concentração de cobre no percolado foi inversamente proporcional às doses aplicadas, com teores inferiores ao valor máximo permitido pela legislação vigente, mesmo tendo sido utilizado solo com carga elevada de calda bordalesa. Entretanto, os teores de cobre medidos nas camadas de topo foram considerados altos. Nos tratamentos com bokashi ultrapassaram o valor de referência de qualidade apontado pela legislação para solos do Estado de São Paulo.

Por outro lado, nos tratamentos com leonardita, houve aumento de concentração de cobre no percolado em função do aumento das doses e a concentração de $\mathrm{Cu}$; total no lixiviado, ultrapassou o limite de potabilidade permitido pela legislação. Em contrapartida, houve maior retenção de $\mathrm{Cu}$ no solo.

São necessários estudos mais detalhados sobre doses e tipos de materiais orgânicos adequados ao controle de $\mathrm{Cu}$, em solo e água, particularmente em sistemas de produção que fazem controle fitossanitário com calda bordalesa. Estudos sobre a utilização continuada de calda bordalesa devem ser obrigatórios para monitorar cuidadosamente solo e água, visando reduzir o risco de contaminação ambiental.

\section{Referências}

ÁLVAREZ-SOLÍS, J. D.; MENDOZA-NÚÑEZ, J. A.; LEÓN-MARTÍNEZ, N. S.; CASTELLANOS-ALBORES, J.; GUTIÉRREZ-MICELI, F. A. Effect of bokashi and vermicompost leachate on yield and quality of pepper (Capsicum annuum) and onion (Allium cepa) under monoculture and intercropping cultures. Ciência e Investigación Agraria, Santiago, v. 43, n.2, p. 243-252,2016.DOI:10.4067/s0718-16202016000200007. Disponível em: https://scielo.conicyt.cl/pdf/ciagr/v43n2/ art07.pdf. Acesso em 22 fev. 2019.

AMARANTE, C.V.T. do; ROSA, E. de F.F. da; ALBUQUERQUE, J. A.; KLAUBERG FILHO, O.; STEFFENS, C. A. Atributos do solo e qualidade de frutos nos sistemas convencional e orgânico de produção de maçãs no Sul do Brasil. Revista Ciência Agronômica, Fortaleza, v. 46, n. 1, p. 99-109, 2015. Disponível em: http://ccarevista.ufc. br/seer/index.php/ccarevista/article/view/3341/1068. Acesso em 26 fev. 2019.

BERTOL, O. J.; FEY, E.; FAVARETTO, N.; LAVORANTI, O. J.; RIZZI, N. E. Mobilidade de $\mathrm{P}, \mathrm{Cu}$ e $\mathrm{Zn}$ em colunas de solo sob sistema de semeadura direta submetido às adubações mineral e orgânica. Revista Brasileira de Ciência do Solo, Viçosa, v. 34, n. 6, p. 1841-1850, 2010. DOI: http://dx.doi.org/10.1590/S0100-06832010000600008. Disponível em: http://www.scielo.br/pdf/rbcs/v34n6/08.pdf. Acesso em 11 abr. 2017.

BORCIONI, E.; MÓGOR, Á. F.; PINTO, F. Aplicação de ácido fúlvico em mudas 
influenciando o crescimento radicular e produtividade de alface americana. Revista Ciência Agronômica, Fortaleza, v. 47, n.3, p. 509-515, 2016. Disponível em: http://ccarevista.ufc. br/seer/index.php/ccarevista/article/view/1782/1417. Acesso em: 18 fev. 2019.

BRADL, H.B. Adsorption of heavy metal ions on soils and soils constituents. Journal of Colloid and Interface Science, New York, v. 277, n. 1, p. 1-18, 2004. DOI: http://dx.doi. org/10.1016/j.jcis.2004.04.005. Disponível em: https:/www.sciencedirect.com/science/ article/pii/S002197970400356X. Acesso em: 18 fev. 2019.

BRASIL. Ministério da Saúde. Secretaria de Vigilância em Saúde. CoordenaçãoGeral de Vigilância em Saúde Ambiental. Portaria MS no 518/2004. Brasília: Editora do Ministério da Saúde, 2005. 28 p. Disponível em: http://bvsms.saude.gov.br/bvs/ publicacoes/portaria_518_2004.pdf. Acesso em: 20 fev. 2019.

BRUNETTO, G.; MELO, G. W. B. DE; KAMINSKI, J.; CERETTA, C. A. Avaliação de teores de cobre em solos cultivados com videira na Serra Gaúcha do Rio Grande do Sul. In: Congresso Brasileiro de Vitivinicultura e Enologia ,12., 2008, Bento Gonçalves, RS. Anais [...]. Bento Gonçalves: Embrapa Uva e Vinho, 2008. p. 95. Disponível em: https://ainfo.cnptia.embrapa.br/digital/bitstream/item/50629/1/BRUNETTO2.pdf. Acesso em: 20 fev. 2019.

BRUNETTO, G.; SCHMITT, D. E.; COMIN, J. J.; MIOTTO, A.; MORAES, M. P. DE; HEINZEN, J. Frações de cobre e zinco em solos de vinhedos no Meio Oeste de Santa Catarina. Revista Brasileira de Engenharia Agrícola e Ambiental, Campina Grande, 2014, v. 18, n. 8, p. 805-810. DOI: https://dx.doi.org/10.1590/1807-1929/agriambi. v18n08p805-810. Disponível em: http://www.scielo.br/pdf/rbeaa/v18n8/v18n08a04.pdf. Acesso em: 22 fev. 2019.

CANELLAS, L. P.; MENDONÇA, E. S.; DOBBSS, L. B.; BALDOTTO, M. A.; VELLOSO, A. C.X.; AMARAL-SOBRINHO, N. M. B. Reações da matéria orgânica. In: SANTOS, G. de A.; SILVA, L. S. da; CANELLAS, L. P.; CAMARGO, F. A. O. (Eds.). Fundamentos de matéria orgânica do solo. Porto Alegre (RS): Gráfica Metrópole, 2008. cap. 05, p. 45-63.

CANELLAS, L. P.; NELSON, G de A. S.; AMARAL SOBRINHO, M. B. do; MORAES, A. A.; RUMJAMEK, V. M. Adsorção de $\mathrm{Cu}^{2+}$ e $\mathrm{Cd}^{2+}$ em ácidos húmicos extraídos de resíduos orgânicos de origem urbana. Ciência Rural, Santa Maria, v. 29, n. 1, p. 21-26,1999.DOI: http://dx.doi.org/10.1590/S0103-84781999000100005. Disponível em: http://www.scielo.br/pdf/cr/v29n1/a05v29n1.pdf. Acesso em: 25 fev. 2019.

CASALI, C. A.; MOTERLE, D. F.; RHEINHEIMER, D. dos S.; BRUNETTO, G.; CORCINI, A. L. M.; KAMINSKI, J.; MELO, G. W. B. de. Formas e dessorção de cobre em solos cultivados com videira na serra gaúcha do Rio Grande do Sul. Revista Brasileira de Ciência do Solo, Viçosa, v. 32, p. 1479-1487, 2008. DOI: http://dx.doi. 
org/10.1590/S0100-06832008000400012.Disponível em: http://www.scielo.br/pdf/rbcs/ v32n4/a12v32n4.pdf. Acesso em: 25 fev. 2017.

COMPANHIA AMBIENTAL DO ESTADO DE SÃO PAULO - CETESB. Valores Orientadores para Solos e Águas Subterrâneas no Estado de São Paulo. CETESB, São Paulo, 2016. Disponível em https://www.cetesb.sp.gov.br/wp-content/ uploads/2014/12/DD-256-2016-E-Valores-Orientadores-Dioxinas-e-Furanos-2016Intranet.pdf. Acesso em: 20 fev. 2019.

CONSELHO NACIONAL DO MEIO AMBIENTE - CONAMA. Resolução 460, de 30 de dezembro de 2013. Altera a Resolução CONAMA 420, de 28 de dezembro de 2009, que dispõe sobre critérios e valores orientadores de qualidade do solo quanto à presença de substâncias químicas e dá outras providências. Diário Oficial [da] União, Brasília, n. 253, 31 dez. 2013, Seção 1, p. 153. Disponível em <http://www2.mma.gov.br/ port/conama/legiabre.cfm?codlegi=702>. Acesso em 21 fev. 2019.

COSTA, D. A.; MENDONÇA, R. H.WYSARDJUNIOR, M.M. Avaliação da remoção de cromo (III) por materiais compósitos porosos adsorventes de PE-g-MA, fibra de coco e quitosana, usando planejamento experimental. Engenharia Sanitária e Ambiental, Rio de Janeiro,v.22, n. 6, p.1203-1213,2017.DOI: 10.1590/S1413-41522017119214.Disponível em: http://www.scielo.br/pdf/esa/v22n6/1809-4457-esa-s1413-41522017119214.pdf. Acesso em: 22 fev. 2019.

CUNHA, C. S. M.; OLIVEIRA, D. P. de; SILVA, C. P. da; GARCIAL, K. G. V.; NASCIMENTO, C. D. V.; OLIVEIRA, E. T. de. Dinâmica do chumbo no ambiente terrestre. Revista Agropecuária Científica no Semiárido, Campina Grande, v. 10, n. 3 , p. 01-10,2014. Disponível em: http://revistas.ufcg.edu.br/acsa/index.php/ACSA/article/ view/545/pdf. Acesso em 25 fev. 2019.

DAVID, P.P.; NELSON,P.V.; SANDERS,D.C.A humic acid improves growth of tomato seedling in solution culture.Journal of Plant Nutrition, Londres,v.17,n.1,p.173-184, 1994. Disponível em: https://www.tandfonline.com/doi/abs/10.1080/01904169409364717. Acesso em: 25 fev. 2019.

EMPRESA BRASILEIRA DE PESQUISA AGROPECUÁRIA - EMBRAPA. Manual de métodos de análise de solo. 2. ed. Rio de Janeiro: Embrapa-CNPS, 1997.212 p.

FELIX, F. F. Comportamento do cobre aplicado no solo por calda bordalesa. 2005. 74 p. Dissertação (Mestrado em Agronomia). Escola Superior de Agricultura Luiz de Queiroz. Piracicaba, SP, 2005.

FERREIRA, J. C. A.; HERNANDES, I; BRITO, O.D. C.; CARDOSO, M. R.; DIASARIEIRA, C. R. Dosages of bokashi in the control of Meloidogyne javanica in lettuce, in greenhouse. Horticultura Brasileira, Vitória da Conquista, v. 35, n. 2, p. 224-229, 2017. 
DOI: http://dx.doi.org/10.1590/s0102-053620170211.Disponível em: http://www.scielo. br/pdf/hb/v35n2/1806-9991-hb-35-02-00224.pdf. Acesso em 18 fev. 2019.

FLORENTINO, A. L.; FERRAZ, A. de V.; GONÇALVES. J. L. de M.; ASENSIO, V.; MURAOKA, T.; DIAS, C. T. dos S.; NOGUEIRA, T. A. R.; CAPRA, G. F.; ABREU-JÚNIOR, C. H. Long-term effects of residual sewage sludge application in tropical soils under Eucalyptus plantations. Journal of Cleaner Production, Amsterdam, n. 22, p. 177-187, 2019. DOI: https://doi.org/10.1016/j. jclepro.2019.02.065. Disponível em: https:/www.sciencedirect.com/science/article/ pii/S0959652619304500. Acesso em 22 fev. 2019.

LIMA, A. A.; ALVARENGA, M. A.R.; RODRIGUES, L.; CARVALHO, J. G. Leaf nutrient content and yield of tomato grown in different substrates and doses of humic acids. Horticultura Brasileira, Brasília, v. 29, n. 1, p. 63-69, 2011. DOI: http://dx.doi. org/10.1590/S0102-05362011000100011. Disponível em: http://www.scielo.br/pdf/hb/ v29n1/11.pdf. Acesso em: 18 fev. 2018.

\section{LOBO, L.M. Substância húmica e fontes de fósforo em Latossolo Vermelho e Neossolo} Quartzarênico. 2015.46 f. Dissertação (Mestrado em Agronomia). Universidade Federal de Goiás, Goiânia, 2015.

LOPES, C.; CAMPOS, M. L.; SILVEIRA, C. B. DA; GATIBONI., L. C.; MIQUELUTTI, D. J.; CASSOL, P. C.; MEDEIROS, Í. DE F. Adsorção de Cu e Zn num Latossolo Vermelho tratado com dejetos suínos. Revista Ceres, Viçosa, v. 61, n. 6, p. 997-1005,2014a. DOI: http://dx.doi.org/10.1590/0034-737X201461060016. Disponível em: http://www.scielo.br/pdf/rceres/v61n6/a16v61n6.pdf. Acesso em: 12 nov. 2016.

LOPES, O. M. M.; CARRILHO, E. N. V. M.; LOPES-ASSAD, M. L. R. C. Effect of rock powder and vinasse on two types of soils. Revista Brasileira de Ciência do Solo, Viçosa, v. 38, n. 5, p. 1547-1557, 2014b. DOI: http://dx.doi.org/10.1590/S010006832014000500020. Disponível em: http://www.scielo.br/pdf/rbcs/v38n5/a20v38n5. pdf. Acesso em: 18 fev. 2019.

MENEGAES,J. F. Avaliação do potencial fitorremediador de plantas floríferas em solo contaminado com cobre. 2015.122 f. Dissertação (Mestrado em Engenharia Agrícola). Universidade Federal de Viçosa, Viçosa, 2015.

MIRLEAN, N.; ROISENBERG, A.; CHIESB, J.O. Metal contamination of vineyard soils in wet subtropics (southern Brazil). Environmental Pollution, Oxford, v. 149, n. 1, p. 10-17, 2007.DOI: https://doi.org/10.1016/j.envpol.2006.12.024. Disponível: https:// www.sciencedirect.com/science/article/pii/S0269749107000048. Acesso em: 17 fev. 2019.

MOREIRA, T. M.; SEO, E. S. M. Caracterização e utilização de fibras de coco como 
biossorvente na recuperação de corpos hídricos contaminados por derramamento de derivados do petróleo. $3^{\circ}$ Congresso Internacional RESAG 2017, 2017, Belo Horizonte. Anais [...], 2017, v. 01, p. 01-14. Disponível em: www.resag.org.br/congressoresag2017/ anais/download/trabalho/151. Acesso em: 22 fev. 2019.

PETRY, H. B.; SCHNEIDER, L. A.; SILVEIRA JÚNIOR, J. C.; CRIZE, T. DE M.; FLÔRES, S. H.; SCHWARZ, S. F. Avaliação física e química e aceitação pelo consumidor de laranjas 'Valência', produzidas sob sistemas de cultivo orgânico e convencional. Ciência Rural, Santa Maria, v. 45, n. 4, p. 619-625, 2015. DOI: http://dx.doi.org/10.1590/01038478cr20131546. Acesso em 25 fev. 2019.

PIMENTEL-GOMES, F. Curso de estatística experimental. 15. ed., Piracicaba: FEALQ 2009, $451 \mathrm{p}$.

RAIJ, B. V.; ANDRADE, J. C.; CANTARELLA, H.; QUAGGIO, J. A. Análise química para avaliação da fertilidade de solos tropicais. Campinas: Instituto Agronômico,2001.285 p.

RODRIGUeS, A. C. D.; SANTOS, A. M.; SAnTOS, F. S.; PEREIRA, A. C. C.; SOBRINHO, N. M. B. A. Mecanismos de respostas das plantas à poluição por metais pesados: possibilidade de uso de macrófitas para remediação de ambientes aquáticos contaminados. Revista Virtual de Química, Niterói, v.8, n. 1, p. 262-276, 2016. Disponível em: http://rvq.sbq.org.br/imagebank/pdf/v8n1a18.pdf. Acesso em: 18 fev. 2019.

SARMENTO, E. B. Avaliação do uso do mesocarpo de "coco verde" como adsorvente de íons cobre $\left(\mathrm{Cu}^{2+}\right)$ presente em águas residuárias industriais. 2017. 64 p. Dissertação (Mestrado em Ciência e Tecnologia Ambiental). Universidade Estadual da Paraíba, Campina Grande, 2017.

SCAVAZZA, A. L.; SOARES, M. R.; CASAGRANDE, J. C.; MEDEIROS, S. D. S. de; DE SANTI, P. H. P. Produção de fitomassa e extração de macronutrientes por plantas de cobertura cultivadas na estação seca. Nativa, Sinop, v. 6, n. 6, p. 619-624, 2018. DOI: http://dx.doi.org/10.31413/nativa.v6i6.5609. Disponível em: http://periodicoscientificos. ufmt.br/ojs/index.php/nativa/article/view/5609. Acesso em: 18 fev. 2019.

SCHWENGBER, J. E.; SCHIEDECK, G.; GONÇALVES, M. de M. Preparo e utilização de caldas nutricionais e protetoras de plantas. Pelotas: Embrapa Clima Temperado, 2007. Disponível em: https://ainfo.cnptia.embrapa.br/digital/bitstream/CPACT/10661/1/ cart_498-06.pdf. Acesso em: 19 fev. 2019.

SEDIYAMA, M. A. N.; SANTOS, I. C. dos; LIMA, P. C. de. Cultivo de hortaliças no sistema orgânico. Revista Ceres, Viçosa, v. 61, supl. p. 829-837, 2014. DOI: http://dx.doi. org/10.1590/0034-737x201461000008. Disponível em: http://www.scielo.br/pdf/rceres/ v61s0/08.pdf. Acesso em: 18 fev. 2019. 
SILVA, K. M. D. da; REZENDE, L. C. S. H.; SILVA, C. A. da; BERGAMASCO, R.; GONÇALVES, D. S. Caracterização físico-química da fibra de coco verde para a adsorção de metais pesados em efluente de indústria de tintas. Engevista, Niterói, v. 15, n. 1, p. 43-50, 2013. DOI: https://doi.org/10.22409/engevista.v15i1.387. Disponível em: http:// periodicos.uff.br/engevista/article/view/8925/6395. Acesso em: 17 abr. 2017.

SILVA, M. L. de S.; VITTI, G. C.; TREVIZAM, A. R. Concentração de metais pesados em grãos de plantas cultivadas em solo com diferentes níveis de contaminação. Pesquisa Agropecuária Brasileira, Brasília, v. 42, n. 4, p. 527-535, 2007. DOI: http://dx.doi. org/10.1590/S0100-204X2007000400011. Disponível em: http:/www.scielo.br/pdf/pab/ v42n4/11.pdf. Acesso em: 19 fev. 2017.

SMANHOTTO, A.; SOUSA, A. de P; SAMPAIO, S. C; NÓBREGA, L. H. P.; PRIOR, M. Cobre e zinco no material percolado e no solo com a aplicação de água residuária de suinocultura em solo cultivado com soja. Engenharia Agrícola, Jaboticabal, v. 30, n. 2, p. 346-357, 2010. DOI: http://dx.doi.org/10.1590/S0100-69162010000200017. Disponível em: http://www.scielo.br/pdf/eagri/v30n2/v30n2a17.pdf. Acesso em: 18 fev. 2017.

SUGIER, D.; KOLODZIEJ, B.; BIELINSKA, E. The effect of application on Arnica montana L. yielding and chosen chemical properties and enzymatic activity of the soil. Journal of Geochemical Exploration, n. 129, p. 76-81, 2013. DOI: https://doi. org/10.1016/j.gexplo.2012.10.013. Disponível em: https:/www.sciencedirect.com/ science/article/pii/S0375674212002130. Acesso em 20 mar. 2017.

TIECHER, T. L. et al. Diagnóstico e interações entre cobre, zinco e fósforo em solos de vinhedos. In: MELO, G. W. B. de; ZALAMENA, J.; BRUNETTO, G.; CERETTA, C. A. (Eds.). Calagem, adubação e contaminação em solos cultivados com videiras. Bento Gonçalves, RS: Embrapa Uva e Vinho, 2016. 138 p. (Documentos, 100). Disponível em: https://ainfo.cnptia.embrapa.br/digital/bitstream/item/147393/1/Doc100.pdf. Acesso em 22 fev. 2019.

TITO, G. A; CHAVES, L. H. G.; GUERRA, H. O. C. Mobilidade do zinco e do cobre em Argissolo com aplicação de argila bentonite. Revista Brasileira de Engenharia Agrícola e Ambiental, Campina Grande, v. 16, n. 9, p. 938-945, 2012. DOI: http:// dx.doi.org/10.1590/S1415-43662012000900003. Disponível em: http:/www.scielo.br/ pdf/rbeaa/v16n9/v16n9a03.pdf. Acesso em: 22 abr. 2017.

VARGAS, C.; PÉREZ-ESTEBAN, J.; ESCOLÁSTICO, C.; MASAGUER, A.; MOLINER, A. Phytoremediation of $\mathrm{Cu}$ and $\mathrm{Zn}$ by vetiver grass in mine soils amended with humic acids. Environmental Science and Pollution Research, Bethesda (MD), v. 23, n. 13, p. 13521-13530, 2016. DOI: 10.1007/s11356-016-6430-x. Disponível em: https://www. ncbi.nlm.nih.gov/pubmed/27030238. Acesso em 22 abr. 2017.

VIANNA JÚNIOR, R. L. Hortas agroecológicas urbanas. Brasília: EMATER-DF, 2015. 36 p. 
VINHAL-FREITAS, I. C.; MALDONADO, A. C. D.; ALVARENGA, C. B.; CAMARGO, R.; WENDLING, B. Adsorção e dessorção de metais no solo e coeficiente de isotermas de Freundlich e Langmuir. Revista Agropecuária Técnica, Areia, v. 31, n. 2, p. 153-163, 2010. DOI: https://doi.org/10.25066/agrotec.v31i2.4516. Disponível em: http://www. periodicos.ufpb.br/ojs/index.php/at/article/view/4516/4637. Acesso em 17 abr. 2017.

ZANDONADI, D. B.; SANTOS, M. P.; MEDICI, L. O.; SILVA, J. Ação da matéria orgânica e suas frações sobre a fisiologia de hortaliças. Horticultura Brasileira, Vitória da Conquista, v. 32, n. 1, p. 14-20, 2014. DOI: https://doi.org/10.1590/S010205362014000100003. Disponível em: http://www.scielo.br/pdf/hb/v32n1/0102-0536hb-32-01-00014.pdf. Acesso em: 20 fev. 2019. 